\title{
Market Risk, Credit Risk, and Futures Trading in Commodity Markets*
}

\author{
Takashi Kanamura ${ }^{\dagger}$
}

May 13, 2012

\begin{abstract}
One of the main purposes to use the futures products in commodity markets is to fill the hedging needs for relatively large market risk and counterparty risk in commodity spot markets. We believe that these two types of market and credit risk will be incorporated into the commodity futures prices. The paper proposes a price model for commodity futures using a new volatility based convenience yield fluctuation and an interest rate fluctuation, which represent the market and credit risk, respectively, in commodity futures markets at the first order approximation. We offer the additional explanation for commodity futures trades such that the futures trades may be conducted for the mitigation of the large spot price volatility in commodity markets characterized by its mean reversion. It is shown that the market risk model, i.e., the new volatility based convenience yield model, can incorporate the inverse hump shape, which is often observed in commodity markets, into the futures term structure and that the interest rate extended model of the market risk model can enhance the contango shape. Empirical studies are conducted using WTI crude oil, heating oil, and natural gas futures traded on the NYMEX. It is shown that the Samuelson effects for heating oil and natural gas futures are captured for both of the proposed models while the Samuelson effects for the WTI crude oil futures are not relevant. In addition, the market risk model using the estimated parameters can demonstrate the inverse hump shape in the crude oil futures term structure and the inclusion of the interest rate model can enhance the contango shape.
\end{abstract}

Key words: Convenience yield, stochastic volatility, commodity futures trading JEL Classification: C51, G13, Q40

\footnotetext{
*Views expressed in this paper are those of the author and do not necessarily reflect those of J-POWER. I am grateful to Toshiki Honda, Matteo Manera, Ryozo Miura, Nobuhiro Nakamura, and Kazuhiko Ōhashi for their useful comments and suggestions. All remaining errors are mine.

${ }_{\dagger}$ J-POWER, 15-1, Ginza 6-Chome, Chuo-ku, Tokyo 104-8165. E-mail: tkanamura@ gmail.com
} 


\section{Introduction}

The hedging needs of commodity price risk are emerging all over the world in the background of the recent commodity boom, where a large number of commodity physical trades are conducted by the suppliers and consumers due to the strong demand from developing countries. Commodity futures markets such as Chicago Mercantile Exchange are used to respond to the risk hedging needs by offering the important alternative trade opportunities both for physical and financial players. We believe that the commodity futures prices quoted in the futures markets will reflect the traded commodity risks. Following the idea, the commodity futures pricing is attempted in this paper.

There are two schools of commodity price models. Gibson and Schwartz (1990), Schwartz (1997), among others propose two-factor model of spot price and convenience yield for commodities. Schwartz and Smith (2000) propose long term and short term model for commodity prices. These models in the first school are referred to as "Reduced models" in the sense that the model hides the structure in economics. In addition, the same reduced type models often used in financial markets are applied to commodity derivative pricing as in e.g., Bjerksund (1991), Yan (2002), Casassus and Collin-Dufresne (2005), Korn (2005), Eydeland and Wolyniec (2003), among others. Paschke and Prokopczuk (2010) have recently incorporated the moving average component into all fluctuation in the futures price returns except long term fluctuation. ${ }^{1}$ These models may be useful to fit well to the historical data. But the structure in economics of commodity markets does not seem to be considered for the modeling. On the other hand, Kanamura (2009) proposes time varying energy price volatility model using the energy economics via the supply and demand relationship. The model in the second school is categorized as "Structural models" in the sense that the structure in economics is incorporated into the model. The model may be useful to capture the characteristics of energy price time

\footnotetext{
${ }^{1}$ The model seems interesting because the moving average, i.e., the high order autoregressive model if invertibility condition holds, is incorporated into the short-term model. However, we do not know if the convenience yields have such moving average property because their short term fluctuation includes the interest rate which fits well to the moving average model as in Benth, Koekebakker, and Zakamouline (2008). In addition, we can not secure any economic reason to hold the moving average component in convenience yield.
} 
varying volatility. However there exists the gap between the time-varying volatility model and the existing reduced, i.e., convenience yield type, models, in particular the futures price models, as in Gibson and Schwartz (1990), Schwartz (1997), among others. The commodity price modeling, in particular the commodity futures price modeling, will be desirable if the modeling is conducted by filling the existing models' gap between the two schools, i.e., by incorporating any structure in economics into the convenience yield.

One of the main purposes to use the futures products in commodity markets is to fill the hedging needs for relatively large market risk and counterparty risk in commodity spot markets. We believe that these two types of market and credit risk will be incorporated into the futures prices, in particular through convenience yield and interest rate. The paper proposes a price model for commodity futures using a new volatility based convenience yield fluctuation and an interest rate fluctuation, which represent the market and credit risk, respectively, in commodity futures markets at the first order approximation. We offer the additional explanation for commodity futures trades such that commodity futures trades may be conducted for the mitigation of large spot price volatility in commodity markets characterized by its mean reversion. It is shown that the market risk model, i.e., the new volatility based convenience yield model, can incorporate the inverse hump shape, which is often observed in commodity markets, into the futures term structure. Then the additional inclusion of an interest rate model into the market risk model demonstrates the enhancement of the contango shape. Empirical studies are conducted using WTI crude oil, heating oil, and natural gas futures traded on the NYMEX. It is shown that the Samuelson effects for heating oil and natural gas futures are captured for both of the proposed models while the Samuelson effects for WTI crude oil futures are not relevant. In addition, the market risk model using the estimated parameters can demonstrate the inverse hump shape in the crude oil futures term structure and the inclusion of the interest rate model can enhance the contango shape.

The remainder of this paper is organized as follows. Section 2 proposes a new price model for commodity futures using the market and credit risk hedging ideas in the commodity futures 
markets. Section 3 conducts empirical studies using WTI crude oil, heating oil, and natural gas futures prices traded on the NYMEX. Section 4 concludes.

\section{The Model}

\subsection{Market Risk Based Price Model for Commodity Futures}

It is well known that commodity prices are determined by the supply-demand relationship. Aligned with this idea, Kanamura (2009) proposed an energy commodity spot price model using the supply-demand relationship:

$$
\begin{aligned}
\frac{d P_{t}}{P_{t}} & =\left(k_{1} \sigma_{t}+k_{2} \sigma_{t}^{2}\right) d t+\sigma_{t} d w_{t}, \\
\sigma_{t} & =\sigma P_{t}^{-a}
\end{aligned}
$$

where $a$ represents the curvature of the supply curve using the inverse Box-Cox transformation function. Here we notice that $\sigma_{t}$ is time varying and may be expressed by a stochastic process. In addition, Kanamura (2009) showed that the price return in the discrete time setting is expressed by GARCH-M(1,1) model as the first order approximation. By using Nelson (1990), we have the continuous time model corresponding to the GARCH model.

$$
d\left(\sigma_{t}^{2}\right)=\left(\omega-\theta \sigma_{t}^{2}\right) d t+\alpha \sigma_{t} d u_{t}
$$

Taking into account that the striking characteristics of commodity price returns are heteroskedastic high volatility, the volatility term and the volatility-driven drift term of Eq. (1) are important for commodity price modeling. It implies that if the spot market for a commodity only exists and the derivative markets including the futures markets are not developed such as immature natural resources markets, the drift term of spot price returns will change dramatically due to the volatility term, in particular in commodity markets and the spot price volatility risk re- 
mains untraded and unhedged in the spot market. Furthermore, the convenience yield often used for commodity pricing does not exist under the supply and demand based commodity pricing.

We suppose the introduction of the commodity futures products in the commodity markets. It is well known that the convenience value to hold the spot products exists in commodity futures markets. As suggested by Schwartz (1997), the convenience yield can be interpreted as the flow of services accruing to the holder of the spot commodity but not to the owner of a futures contract. It implies that the existence of the futures products by itself can secure the value to hold the spot products through the absence of no arbitrage. To this end, the drift term of spot price returns is gradually approaching to the linear function of the mean-reverting convenience yield. Hence we can interpret the introduction of the futures trades as the tool to make the spot price return drift term stationary, i.e., mean reversion:

$$
\begin{aligned}
\frac{d P_{t}}{P_{t}} & =\left(a-\delta_{t}\right) d t+\sigma_{t} d w_{t} \\
d \delta_{t} & =\kappa\left(\bar{\mu}-\delta_{t}\right) d t+\bar{\sigma}_{\delta} \sqrt{\delta_{t}} d z_{t}
\end{aligned}
$$

As one of the famous characteristics of the convenience yield, the convenience yield increases in the spot price volatility because the convenience yield is considered as the option value to hold the commodity. In addition, since the inverse leverage effects ${ }^{2}$ are often observed in commodity markets as in Geman (2005), the convenience yield may be an increasing function of the prices. To secure the characteristics, we examine the relationship between 1-month futures prices and convenience yields of WTI crude oil from December 3, 2007 to March 31, 2008. ${ }^{3}$ The results are reported in Figure 1, implying that the convenience yield tend to increase in the price.

\section{[INSERT FIGURE 1 ABOUT HERE]}

\footnotetext{
${ }^{2}$ The volatility increases in the price.

${ }^{3}$ The convenience yield is calculated using $\delta_{t} \equiv \ln F_{t}^{T}-\ln F_{t}^{S}$ where $F_{t}^{T}$ and $F_{t}^{S}$ are 1- and 6- month WTI futures prices, respectively.
} 
The idea gives us the reasonable assumption that the convenience yield is defined by the linear function of the spot price volatility as the first order approximation: ${ }^{4}$

$$
\delta_{t}=b V_{t}=b \sigma_{t}^{2}
$$

with $b>0 .^{5}$ Taking into account $V_{t}$ is the spot price volatility, the spot market risk is spanned by the convenience yield, which emerges due to the commodity futures market development. By using the relationship we propose a commodity price model:

$$
\begin{aligned}
& \frac{d P_{t}}{P_{t}}=\left(a-\delta_{t}\right) d t+\bar{\sigma}_{P} \sqrt{\delta_{t}} d w_{t} \\
& d \delta_{t}=\kappa\left(\bar{\mu}-\delta_{t}\right) d t+\bar{\sigma}_{\delta} \sqrt{\delta_{t}} d z_{t}
\end{aligned}
$$

where $\bar{\sigma}_{P}=\frac{\sigma_{P}}{\sqrt{b}}, \bar{\sigma}_{\delta}=\sigma_{V} \sqrt{b}, \bar{\mu}=b \mu$, and $E\left[d w_{t} d z_{t}\right]=\rho d t$. Hence the convenience yield process has $\sqrt{\delta_{t}}$ in the volatility term referred to as the CIR model, which secures non negative $\delta_{t}$. Thus, the volatility risk of commodity spot prices, which is large in commodity markets, is directly linked to a mean reverting convenience yield. More importantly, the model can offer the interpretation that the spot market price volatility, i.e., the market risk, is spanned by the convenience yields.

\footnotetext{
${ }^{4}$ One may think that there exists a constant term in Eq. (6). But the convenience yield can be set in a way to build the constant in.

${ }^{5}$ As the volatility-in-mean model for the spot price returns including stochastic volatility, there exists a following stochastic volatility model as in e.g., Singleton (2006). Note that we assume the drift term mean reverts:

$$
\begin{aligned}
& \frac{d P_{t}}{P_{t}}=\left(a-b V_{t}\right) d t+\sigma_{P} \sqrt{V_{t}} d w_{t}, \\
& d V_{t}=\kappa\left(\mu-V_{t}\right) d t+\sigma_{V} \sqrt{V_{t}} d z_{t}
\end{aligned}
$$

where $b>0$ and $E\left[d w_{t} d z_{t}\right]=\rho d t$. Then we consider the relation between the stochastic volatility model and the convenience yield type model. Commodity market model incorporates the convenience yield into the drift term such that $E\left[\frac{d P_{t}}{P_{t}}\right]=\left(a-\delta_{t}\right) d t$. The specification gives us the relationship such that $\delta_{t}=b V_{t}$.
} 
We try to model the commodity futures prices using the spot price model we proposed. Here we assume the following stochastic processes under the risk neutral measure.

$$
\begin{aligned}
\frac{d P_{t}}{P_{t}} & =\left(r-\delta_{t}\right) d t+\bar{\sigma}_{P} \sqrt{\delta_{t}} d w_{t}^{*} \\
d \delta_{t} & =\kappa\left(\bar{\mu}-\frac{\lambda}{\kappa}-\delta_{t}\right) d t+\bar{\sigma}_{\delta} \sqrt{\delta_{t}} d z_{t}^{*}
\end{aligned}
$$

Note that we define the market price of risk and the market price of convenience yield, i.e., volatility risk by $\phi_{P}=\frac{a-r}{\bar{\sigma}_{P} \sqrt{\delta_{t}}}$ and $\phi_{V}=\frac{\lambda}{\bar{\sigma}_{\delta} \sqrt{\delta_{t}}}$, respectively. Following e.g., Schwartz (1997), we assume that commodity futures prices are given by

$$
F(P, \delta, t, T)=P \exp (A(t, T)-B(t, T) \delta)
$$

Under the risk neutral measure, we found that the coefficients $A(t, T)$ and $B(t, T)$ are given by

$$
\begin{aligned}
& B(t, T)=\alpha \beta\left(\frac{1-\exp \left(-\frac{1}{2}(\alpha-\beta) \bar{\sigma}_{\delta}^{2}(T-t)\right)}{\beta-\alpha \exp \left(-\frac{1}{2}(\alpha-\beta) \bar{\sigma}_{\delta}^{2}(T-t)\right)}\right) \\
& A(t, T)=-(\alpha(\kappa \bar{\mu}-\lambda)-r)(T-t)+\frac{2 \alpha}{\bar{\sigma}_{\delta}^{2}}(\kappa \bar{\mu}-\lambda) \ln \left|\frac{\beta-\alpha \exp \left(-\frac{1}{2}(\alpha-\beta) \bar{\sigma}_{\delta}^{2}(T-t)\right)}{\beta-\alpha}\right|
\end{aligned}
$$

where $\alpha$ and $\beta(\alpha>\beta)$ are expressed by the solutions

$$
x=\frac{\rho \bar{\sigma}_{P} \bar{\sigma}_{\delta}-\kappa \pm \sqrt{\left(\rho \bar{\sigma}_{P} \bar{\sigma}_{\delta}-\kappa\right)^{2}+2 \bar{\sigma}_{\delta}^{2}}}{\bar{\sigma}_{\delta}^{2}} .
$$

Note that $P \mathrm{~s}, \delta \mathrm{s}$, and $F \mathrm{~s}$ are commodity spot prices, the convenience yields, and the futures prices, respectively. Thus the explicit model is obtained using the spot price model proposed in this paper. The model is referred to as "Market Risk-Based (MR) Price Model for Commodity Futures." 
Then looking at the futures price model, commodity futures price risks are spanned by the spot price and convenience yield. Taking into account that the convenience yield comes from the spot price volatility in the model framework, the futures price risks turn out to be spanned by the spot price volatility risks. That is, the volatility risks in commodity spot prices are traded using the futures products. Recall that the futures market development generates the mean-reverting convenience yield, which is built in the spot price volatility. The spot price volatility is considered to be handled using the mean reversion of convenience yield under the existence of the futures markets. Thus, the futures trading may be useful to reduce the spot price volatility, which is generally large in commodity markets due to the supply and demand relationship in the way that the spot price volatility mean reverts. In turn, we can also say that commodity futures trades are conducted to mitigate the high spot price volatility in commodity markets.

Next, we try to examine the term structure of the commodity futures prices in the model framework we presented. By using Ito's Lemma, we have

$$
\frac{1}{d t} V\left[\frac{d F}{F}\right]=\left[\bar{\sigma}_{P}^{2}+B(t, T)^{2} \bar{\sigma}_{\delta}^{2}-2 B(t, T) \bar{\sigma}_{P} \bar{\sigma}_{\delta} \rho\right] \delta_{t} \equiv\left(\sigma_{F, t}^{T}\right)^{2}
$$

Hence, the futures price return volatility heavily depends on both time-varying coefficient $B(t, T)$ and convenience yield $\delta_{t}$. By a simple calculation, we obtain

$$
\frac{\partial\left(\sigma_{F, t}^{T}\right)^{2}}{\partial \tau}=2 \bar{\sigma}_{\delta}\left[B(\tau) \bar{\sigma}_{\delta}-\bar{\sigma}_{P} \rho\right] \delta_{t} \frac{\partial B(\tau)}{\partial \tau}
$$

where $\tau \equiv T-t$. The term structure of commodity futures prices demonstrates contango and/or backwardation depending on the positive or negative sign of the block bracket in the RHS of Eq. (18) because $\frac{\partial B(\tau)}{\partial \tau}=-\frac{1}{2} \alpha \beta(\alpha-\beta)^{2}\left(\frac{\exp \left(-\frac{1}{2}(\alpha-\beta) \bar{\sigma}_{\delta}^{2}(T-t)\right)}{\left(\beta-\alpha \exp \left(-\frac{1}{2}(\alpha-\beta) \bar{\sigma}_{\delta}^{2}(T-t)\right)\right)^{2}}\right) \bar{\sigma}_{\delta}^{2}>0$ using $\alpha \beta<0$. More interestingly, the mixture of the backwardation and contango implies that the market risk model, i.e., a new volatility based convenience yield model, can incorporate the inverse hump shape into the futures term structure. The property is consistent with the market 
observation such that the high volatility in commodity spot prices, as observed in winter natural gas markets, causes the backwardation in the near term structure but the contango in the long term structure.

\subsection{Market and Credit Risk Based Price Model for Commodity Futures}

So far we assumed that the interest rate is constant. But in reality, it is well known that the interest rate fluctuates stochastically. We introduce an independent stochastic interest rate model, i.e., the CIR type model, in the previous model to reflect the real market situation and to examine the impact of the interest rate on commodity futures curves. We assume the following stochastic processes under the risk neutral measure.

$$
\begin{aligned}
\frac{d P_{t}}{P_{t}} & =\left(r_{t}-\delta_{t}\right) d t+\bar{\sigma}_{P} \sqrt{\delta_{t}} d w_{t}^{*} \\
d \delta_{t} & =\kappa\left(\bar{\mu}-\frac{\lambda}{\kappa}-\delta_{t}\right) d t+\bar{\sigma}_{\delta} \sqrt{\delta_{t}} d z_{t}^{*} \\
d r_{t} & =k_{r}\left(\mu_{r}-r_{t}\right) d t+\bar{\sigma}_{r} \sqrt{r_{t}} d u_{t}^{*}
\end{aligned}
$$

where $E^{*}\left[d w_{t}^{*} d u_{t}^{*}\right]=E^{*}\left[d z_{t}^{*} d u_{t}^{*}\right]=0$. Following e.g., Schwartz (1997), we assume that commodity futures prices are represented by

$$
F(P, \delta, r, t, T)=P \exp (A(t, T)-B(t, T) \delta+C(t, T) r)
$$


Under the risk neutral measure, we found that the coefficients $A(t, T)$ and $B(t, T)$ are expressed by

$$
\begin{aligned}
B(t, T)= & \alpha \beta\left(\frac{1-\exp \left(-\frac{1}{2}(\alpha-\beta) \bar{\sigma}_{\delta}^{2}(T-t)\right)}{\beta-\alpha \exp \left(-\frac{1}{2}(\alpha-\beta) \bar{\sigma}_{\delta}^{2}(T-t)\right)}\right) \\
C(t, T)= & p q\left(\frac{1-\exp \left(\frac{1}{2}(p-q) \bar{\sigma}_{r}^{2}(T-t)\right)}{q-p \exp \left(\frac{1}{2}(p-q) \bar{\sigma}_{r}^{2}(T-t)\right)}\right) \\
A(t, T)= & -\left(\alpha(\kappa \bar{\mu}-\lambda)-p \kappa_{r} \mu_{r}\right)(T-t)+\frac{2 \alpha}{\bar{\sigma}_{\delta}^{2}}(\kappa \bar{\mu}-\lambda) \ln \left|\frac{\beta-\alpha \exp \left(-\frac{1}{2}(\alpha-\beta) \bar{\sigma}_{\delta}^{2}(T-t)\right)}{\beta-\alpha}\right| \\
& +\frac{2 p}{\bar{\sigma}_{r}^{2}} \kappa_{r} \mu_{r} \ln \left|\frac{q-p \exp \left(\frac{1}{2}(p-q) \bar{\sigma}_{r}^{2}(T-t)\right)}{q-p}\right|
\end{aligned}
$$

where $\alpha$ and $\beta(\alpha>\beta)$ are expressed by Eq. (16) and where $p$ and $q(p>q)$ are expressed by the solutions

$$
x=\frac{\kappa_{r} \pm \sqrt{\kappa_{r}^{2}-2 \bar{\sigma}_{r}^{2}}}{\bar{\sigma}_{r}^{2}} .
$$

Here we try to think of the relationship between credit risk and interest rate in commodity futures markets. The companies using the central clearing counterparty role of the futures markets, in advance, pay to the futures markets the necessary margins, which are basically managed using money account. Thus, regarding commodity futures markets it can be considered that in commodity futures markets the interest rates reflect the credit risk embedded in the commodity futures trading as the first order approximation. It implies that the futures prices are spanned by the credit risk through the interest rates. Taking into account that the convenience yields span the market risk in our framework, the model is referred to as "Market and Credit Risk-Based (MCR) Price Model for Commodity Futures.” Thus the explicit model is obtained using the spot price model proposed in this paper.

In the same to the two factor model, we examine the relationship between the commodity futures curve and the interest rate model injection. By using Ito's Lemma, we have

$$
\frac{1}{d t} V\left[\frac{d F}{F}\right]=\left[\bar{\sigma}_{P}^{2}+B(t, T)^{2} \bar{\sigma}_{\delta}^{2}-2 B(t, T) \bar{\sigma}_{P} \bar{\sigma}_{\delta} \rho\right] \delta_{t}+C(t, T)^{2} \bar{\sigma}_{r}^{2} r_{t} \equiv\left(\sigma_{F, t}^{T}\right)^{2}
$$


Hence, the futures price return volatility heavily depends on time-varying coefficients of $B(t, T)$ and $C(t, T)$, convenience yield $\delta_{t}$, and interest rate $r_{t}$. By a simple calculation, we obtain

$$
\frac{\partial\left(\sigma_{F, t}^{T}\right)^{2}}{\partial \tau}=2 \bar{\sigma}_{\delta}\left[B(\tau) \bar{\sigma}_{\delta}-\bar{\sigma}_{P} \rho\right] \delta_{t} \frac{\partial B(\tau)}{\partial \tau}+2 C(\tau) \frac{\partial C(\tau)}{\partial \tau} b a r \sigma_{r}^{2} r_{t}
$$

where $\tau \equiv T-t$. The impact of the convenience yield of the future curve is the same as the impact in the two factor model, demonstrating contango or backwardation depending on the positive or negative sign of the block bracket in the RHS of Eq. (28). In contrast, the term structure of commodity futures prices demonstrates the positive impact of interest rates on the future curve because $\frac{\partial C(\tau)}{\partial \tau}=\frac{1}{2} p q(p-q)^{2} \overline{\boldsymbol{\sigma}}_{r}^{2}\left(\frac{\exp \left(\frac{1}{2}(p-q) \overline{\boldsymbol{\sigma}}_{r}^{2}(T-t)\right)}{\left(q-p \exp \left(\frac{1}{2}(p-q) \overline{\boldsymbol{\sigma}}_{r}^{2}(T-t)\right)\right)^{2}}\right)>0$ and $C(\tau)>0$ using $p q>0$. Thus the interest rate enhances the upward sloping regarding, i.e., contango in the future curve.

\section{Empirical Studies}

\subsection{Data}

In this study, we use the daily closing prices of WTI crude oil (WTI), heating oil (HO), and natural gas (NG) futures traded on the NYMEX. Each futures product includes six delivery months - from one month to six months. The covered time period is from April 3, 2000 to March 31, 2008. The data are obtained from Bloomberg. Summary statistics for WTI, HO, and NG futures prices are provided in Panels A, B, and C of Table 1, respectively. These panels indicate that all of WTI, HO, and NG have common skewness characteristics. The skewness of WTI, HO, and NG futures prices is positive, meaning that the distributions are skewed to the right.

[INSERT TABLE 1 ABOUT HERE] 


\subsection{MR Price Model Parameter Estimation}

For the reason of the model parsimony, we first estimate the two-factor model parameters employing the Kalman filter $(\mathrm{KF})$. To simplify the calculation, we log transform the spot price $P_{t}$ into new variable $x_{t}$ :

$$
d x_{t}=\left(a-\left(1+\frac{1}{2} \bar{\sigma}_{P}^{2}\right) \delta_{t}\right) d t+\bar{\sigma}_{P} \sqrt{\delta_{t}} d w_{t}
$$

$\mathrm{KF}$ consists of time and measurement update equations. On one hand, since $x$ and $\delta$ in Eqs. (29) and (10), respectively are time updated, these equations represent the linear time update equations in the KF system. We discretize the continuous-time model for $x$ in Eq. (29) into

$$
x_{t}=x_{t-1}+\left(a-\left(1+\frac{1}{2} \bar{\sigma}_{P}^{2}\right) \delta_{t-1}\right) \Delta t+\sigma_{P} \sqrt{\delta_{t-1}} \varepsilon_{t} \equiv f_{1}\left(x_{t-1}, \delta_{t-1}, \varepsilon_{t}\right) .
$$

Similarly, the continuous-time model for $\delta$ in Eq. (10) into the following:

$$
\delta_{t}=(1-\kappa \Delta t) \delta_{t-1}+\kappa\left(\bar{\mu}-\frac{\lambda}{\kappa}\right) \Delta t+\bar{\sigma}_{\delta} \sqrt{\delta_{t-1}} \eta_{t} \equiv f_{2}\left(x_{t-1}, \delta_{t-1}, \eta_{t}\right)
$$

On the other hand, the measurement update equation in the KF system is obtained from the futures-spot price relationship. We define the $\log$ of $F_{t}^{T}$ by the new variable $y_{t}\left(y_{t}=\ln F_{t}^{T}\right)$, and discretize the logarithm of the both sides of Eq. (13) into the following:

$$
y_{t}=x_{t}-B(t, T) \delta_{t}+A(t, T)+\xi_{t} \equiv h_{1}\left(x_{t}, \delta_{t}, \xi_{t}\right)
$$

Following Welch and Bishop (2004), time and measurement update equations are expressed by

$$
\left(\begin{array}{c}
x_{t} \\
\delta_{t}
\end{array}\right)=\left(\begin{array}{c}
\tilde{x}_{t} \\
\tilde{\delta}_{t}
\end{array}\right)+A_{t}\left(\begin{array}{c}
x_{t-1}-\hat{x}_{t-1} \\
\delta_{t-1}-\hat{\delta}_{t-1}
\end{array}\right)+W_{t}\left(\begin{array}{c}
\varepsilon_{t} \\
\eta_{t}
\end{array}\right),
$$




$$
y_{t}=h_{1}\left(\tilde{x}_{t}, \tilde{\delta}_{t}, 0\right)+B_{t}\left(\begin{array}{c}
x_{t}-\tilde{x}_{t} \\
\delta_{t}-\tilde{\delta}_{t}
\end{array}\right)+V_{t} \xi_{t}
$$

where $\tilde{x}_{t}=f_{1}\left(\hat{x}_{t-1}, \hat{\delta}_{t-1}, 0\right), \tilde{\delta}_{t}=f_{2}\left(\hat{x}_{t-1}, \hat{\delta}_{t-1}, 0\right), A_{t}=\left(\begin{array}{cc}1 & -\left(1+\frac{1}{2} \bar{\sigma}_{P}^{2}\right) \Delta t \\ 0 & 1-\kappa \Delta t\end{array}\right)$,

$W_{t}=\left(\begin{array}{cc}\bar{\sigma}_{P} \sqrt{\delta_{t-1}} & 0 \\ 0 & \bar{\sigma}_{\delta} \sqrt{\delta_{t-1}}\end{array}\right), B_{t}=\left(\begin{array}{cc}1 & -B(t, T)\end{array}\right), V_{t}=1, V\left[\varepsilon_{t}, \eta_{t}\right]=Q_{t}=\left(\begin{array}{cc}\Delta t & \rho \Delta t \\ \rho \Delta t & \Delta t\end{array}\right)$,

and

$V\left[\xi_{t}\right]=R_{t}=\operatorname{diag}\left[m_{1}, m_{2}, m_{3}, m_{4}, m_{5}, m_{6}\right]$ where $m_{i}>0$ (Diagonal matrix).

Tables 2 and 3 show the complete set of the KF equations which include time and measurement update equations so as to calculate the a priori estimate error covariance matrix $\left(\Phi_{t}^{-}\right)$ and the a posteriori estimate error covariance matrix $\left(\Phi_{t}\right)$, respectively.

\section{[INSERT TABLE 2 ABOUT HERE]}

\section{[INSERT TABLE 3 ABOUT HERE]}

Note that we define the a priori estimate error and the covariance by $e_{t}^{-} \equiv\left(\begin{array}{c}x_{t}-\hat{x}_{t}^{-} \\ \delta_{t}-\hat{\delta}_{t}^{-}\end{array}\right)$ and $\Phi_{t}^{-} \equiv E\left[e_{t}^{-} e_{t}^{-T}\right]$, and that we also define the a posteriori estimate error and the covariance by $e_{t} \equiv\left(\begin{array}{c}x_{t}-\hat{x}_{t} \\ \delta_{t}-\hat{\delta}_{t}\end{array}\right)$ and $\Phi_{t} \equiv E\left[e_{t} e_{t}^{T}\right]$ where $K_{t}$ is the Kalman gain.

Using the recursive updates of time and measurement update equations as in Tables 2 and 3 , measurement errors $\left(\tilde{e}_{y_{t}}\right)$ and the covariance matrices $\left(\Sigma_{t}\right)$ are given by

$$
\begin{gathered}
\tilde{e}_{y_{t}}=y_{t}-h_{1}\left(\hat{x}_{t}^{-}, \hat{\delta}_{t}^{-}, 0\right), \\
\Sigma_{t}=B_{t} \Phi_{t}^{-} B_{t}^{T}+V_{t} R_{t} V_{t}^{T} .
\end{gathered}
$$


Using the measurement errors and the covariance matrices, the parameters $(\Theta)$ in Eqs. (9) and (10) are estimated by the maximum likelihood method

$$
\hat{\Theta}=\arg \min _{\Theta} \sum_{t=1}^{N} \ln \left|\Sigma_{t}\right|+\sum_{t=1}^{N} \tilde{e}_{y_{t}} \Sigma_{t}^{-1} \tilde{e}_{y_{t}}^{T}
$$

where $\Theta=\left(a, \bar{\sigma}_{P}, \kappa, \bar{\mu}, \bar{\sigma}_{\delta}, \rho, \lambda, m_{1}, m_{2}, m_{3}, m_{4}, m_{5}, m_{6}\right)$. Note that risk free rate $r$ is set to $6 \%$.

[INSERT TABLE 4 ABOUT HERE]

[INSERT TABLE 5 ABOUT HERE]

\section{[INSERT TABLE 6 ABOUT HERE]}

All parameters in the three tables are statistically significant. The $\rho$ s are estimated as positive values $(0.627,0.697$, and 1.000 , resp.), i.e., both of the price volatility and convenience yields have the positive relation to the spot prices. It implies that the volatility is positively correlated with the price returns, which is referred to as "Inverse leverage effect" often observed in commodity markets. It is consistent with commodity market observation and the original characteristics of the convenience yield as an option. Using the parameters in Tables 4, 5, and 6, we calculated the volatility in Eq. (27). The results are reported in Figures 2, 3, and 4, respectively. The figures suggest that the volatility decreases in the time to maturity for heating oil and natural gas futures, resulting in the Samuelson effect often observed in energy markets, while the crude oil futures volatility does not tend to demonstrate the Samuelson effect. This may come from higher liquidity and more efficiency of crude oil futures market than heating oil and natural gas futures markets. In particular, the crude oil futures term structure in Figure 2 demonstrates the inverse hump shape such that the volatility decreases in the time to maturity in small time to maturity region then the volatility increases in the time to maturity in long time to maturity region. More interestingly, by changing the convenience yield level from 1 to 2 in Figure 2 the curvature of the inverse hump shape becomes sharp. The result is consistent with the model implication. 
[INSERT FIGURE 2 ABOUT HERE]

[INSERT FIGURE 3 ABOUT HERE]

[INSERT FIGURE 4 ABOUT HERE]

\subsection{MCR Price Model Parameter Estimation}

By following Kladívko (2007), we estimate the CIR interest rate model by using the data from April 3, 2000 to March 31, 2008. The results are reported in Table 7. The other two parameters other than $\bar{\mu}_{r}$ are statistically significant.

\section{[INSERT TABLE 7 ABOUT HERE]}

Using the parameter estimation method in Schwartz (1997) we obtained the three factor model parameters for WTI crude oil, heating oil, and natural gas futures in Tables 8, 9, and 10. All parameters in the three tables are statistically significant. The $\rho$ s are estimated as positive values $(0.020,0.855$, and 0.752 , resp.), i.e., both of the price volatility and convenience yields have the positive relation to the spot prices. It implies that the volatility is positively correlated with the price returns, which is referred to as "Inverse leverage effect" often observed in commodity markets. It is consistent with commodity market observation and the original characteristics of the convenience yield as an option.

[INSERT TABLE 8 ABOUT HERE]

[INSERT TABLE 9 ABOUT HERE]

[INSERT TABLE 10 ABOUT HERE] 
We illustrate in Figures 5, 6, and 7 the impacts of interest rates on the crude oil, heating oil, and natural gas futures curves, respectively. The figures suggest that the volatility decreases in the time to maturity for heating oil and natural gas futures, resulting in the Samuelson effect often observed in energy markets, while the crude oil futures curve does not tend to demonstrate the Samuelson effect. More importantly, all three figures indicate that the futures curves demonstrate strong contango when the interest rate impacts on the curves become large, i.e., $r / \delta$ increases. The results are consistent with the model examination conducted in the previous model part.

\author{
[INSERT FIGURE 5 ABOUT HERE]
}

[INSERT FIGURE 6 ABOUT HERE]

\author{
[INSERT FIGURE 7 ABOUT HERE]
}

\title{
4. Conclusions
}

One of the main purposes to use the futures products in commodity spot markets lie in the hedging needs for relatively large market risk and counterparty risk. We believed that these two types of market and credit risk will be incorporated into the futures prices. The paper proposed a price model for commodity futures using a new volatility based convenience yield fluctuation and an interest rate fluctuation, which represent the market and credit risk, respectively, in commodity futures markets at the first order approximation. We have offered the additional explanation for commodity futures trades such that the futures trades may be conducted for the mitigation of large spot price volatility in commodity markets characterized by its mean reversion. It was shown that the market risk model, i.e., the new volatility based convenience yield model, can incorporate the inverse hump shape, which is often observed in commodity markets, into the futures term structure. Then the additional inclusion of an 
interest rate model into the market risk model demonstrated the enhancement of the contango shape. Empirical studies were conducted using WTI crude oil, heating oil, and natural gas futures traded on the NYMEX. It was shown that the Samuelson effects for heating oil and natural gas futures are captured for both of the proposed models while the Samuelson effects for WTI crude oil futures are not relevant. In addition, the market risk model using the estimated parameters can demonstrate the inverse hump shape in the crude oil futures term structure and the inclusion of the interest rate model can enhance the contango shape. 


\section{References}

Benth, F., S. Koekebakker, and V. Zakamouline, 2008, The CARMA interest rate model, Working paper, University of Oslo and University of Agder.

Bjerksund, P., 1991, Contingent Claims Evaluation when the Convenience Yield is Stochastic: Analytical Results, Working paper, Norwegian School of Economics and Business Administration.

Casassus, J., and P. Collin-Dufresne, 2005, Stochastic Convenience Yield Implied from Commodity Futures and Interest Rates, Journal of Finance 60, 2283-2331.

Eydeland, A., and K. Wolyniec, 2003, Energy and Power Risk Management: New Developments in Modeling, Pricing, and Hedging. (John Wiley \& Sons, Inc. Hoboken).

Geman, H., 2005, Commodities and Commodity Derivatives. (John Wiley \& Sons Ltd West Sussex).

Gibson, R., and E. Schwartz, 1990, Stochastic Convenience Yield and the Pricing of Oil Contingent Claims, Journal of Finance 45, 959-976.

Kanamura, T., 2009, A supply and demand based volatility model for energy prices, Energy Economics $31,736-747$.

Kladivko, K., 2007, Maximum likelihood estimation of the Cox-Ingersoll-Ross process: the Matlab implementation, Working paper, Technical Computing Prague.

Korn, O., 2005, Drift Matters: An Analysis of Commodity Derivatives, The Journal of Futures Markets $25,211-241$.

Nelson, D., 1990, ARCH Models as Diffusion Approximations, Journal of Econometrics 45, 7-38.

Paschke, R., and M. Prokopczuk, 2010, Commodity derivatives valuation with autoregressive and moving average components in the price dynamics, Journal of Banking \& Finance 34, 2742-2752.

Schwartz, E., and J. Smith, 2000, Short-Term Variations and Long-Term Dynamics in Commodity Prices, Management Science 46, 893-911.

Schwartz, E. S., 1997, The Stochastic Behaviour of Commodity Prices: Implication for Valuation and Hedging, Journal of Finance 52, 923-973. 
Singleton, K., 2006, Empirical Dynamic Asset Pricing: Model Specification and Econometric Assessment. (Princeton University Press. Princeton).

Welch, G., and G. Bishop, 2004, An Introduction to the Kalman Filter, Working paper, University of North Carolina at Chapel Hill.

Yan, X., 2002, Valuation of Commodity Derivatives in a New Multi-Factor Model, Review of Derivatives Research 5, 251-271. 


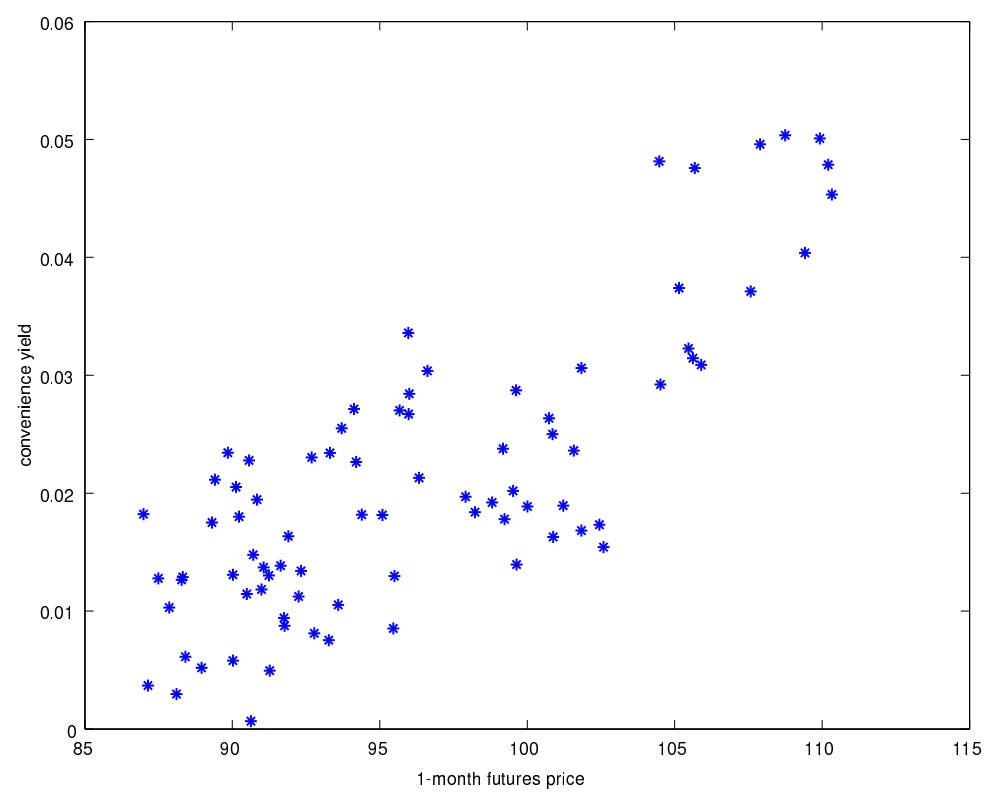

Figure 1. Relationship between 1-Month Futures Prices and Convenience Yields

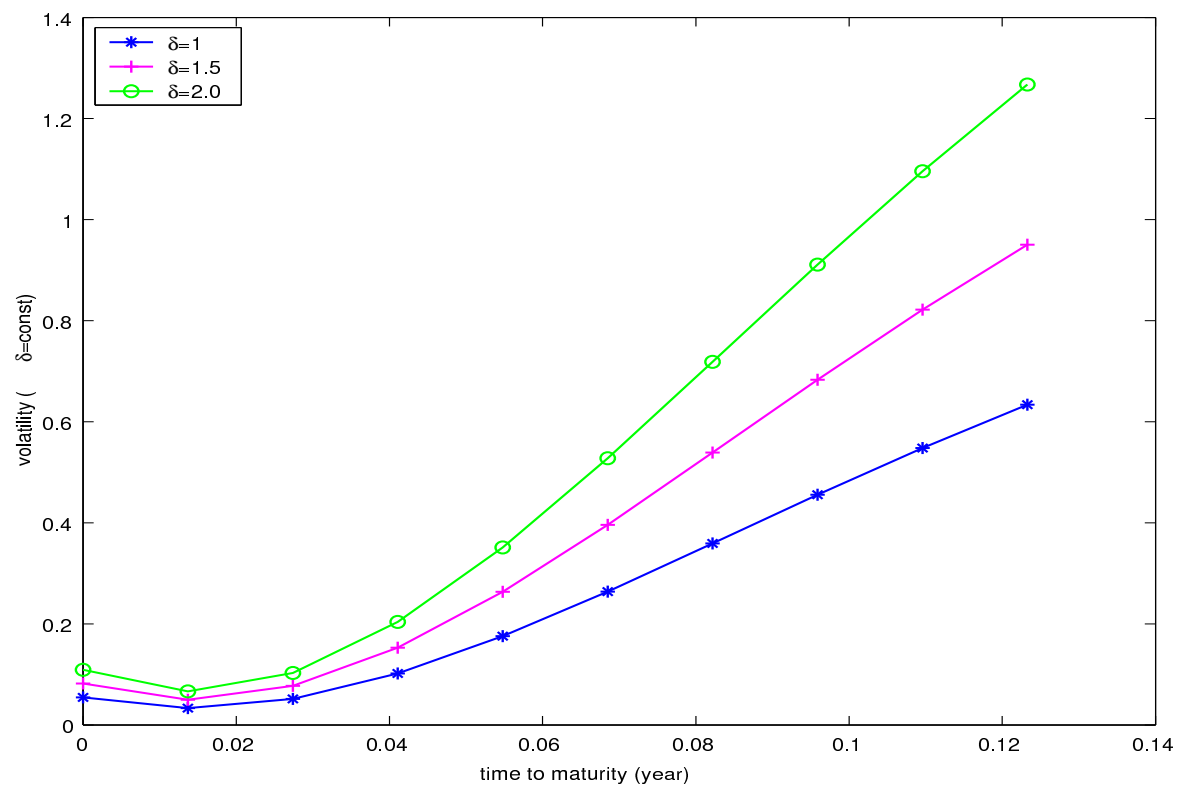

Figure 2. Relationship between Volatility and Time to Maturity for Crude Oil 


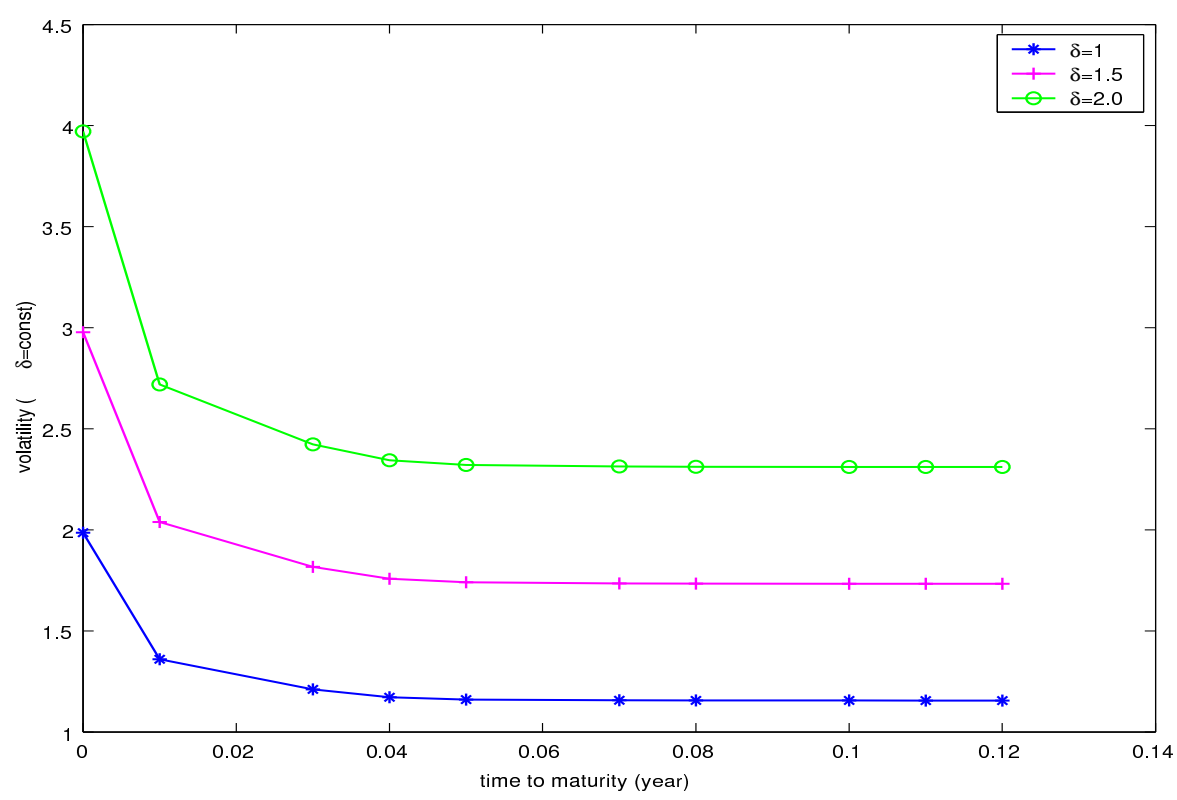

Figure 3. Relationship between Volatility and Time to Maturity for Heating Oil

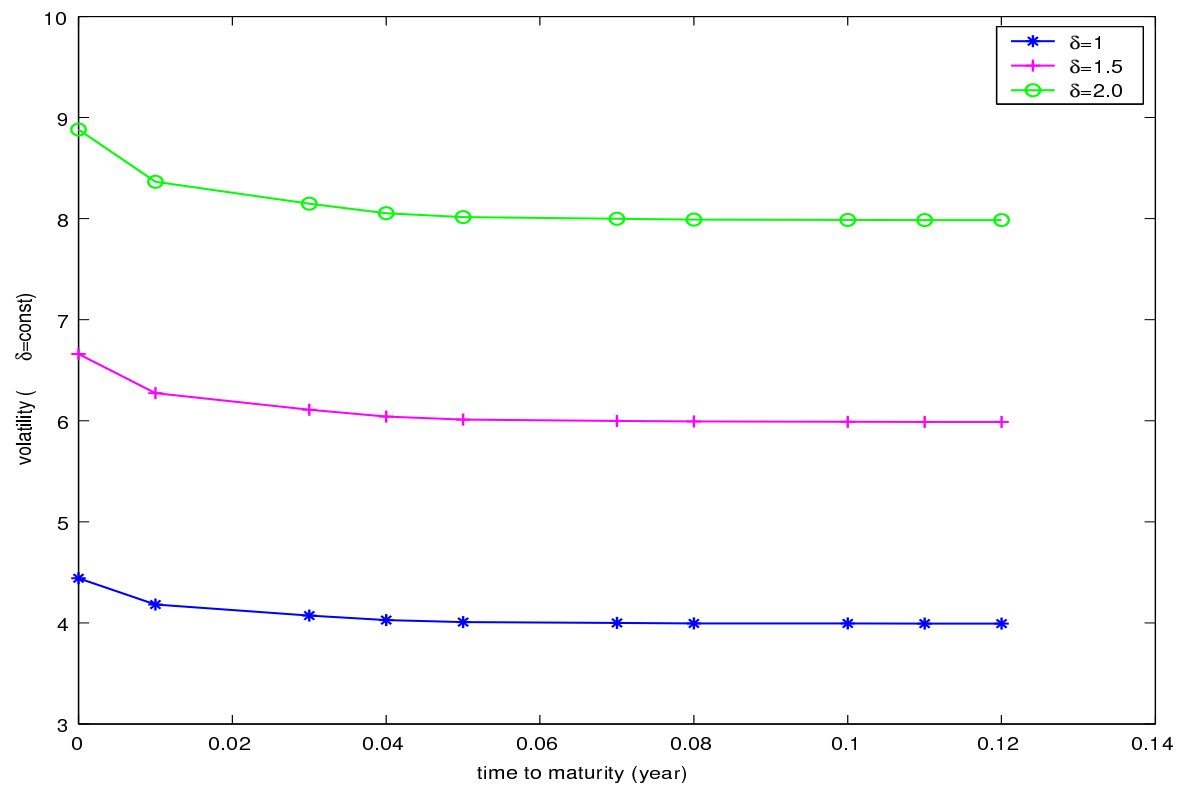

Figure 4. Relationship between Volatility and Time to Maturity for Natural Gas 


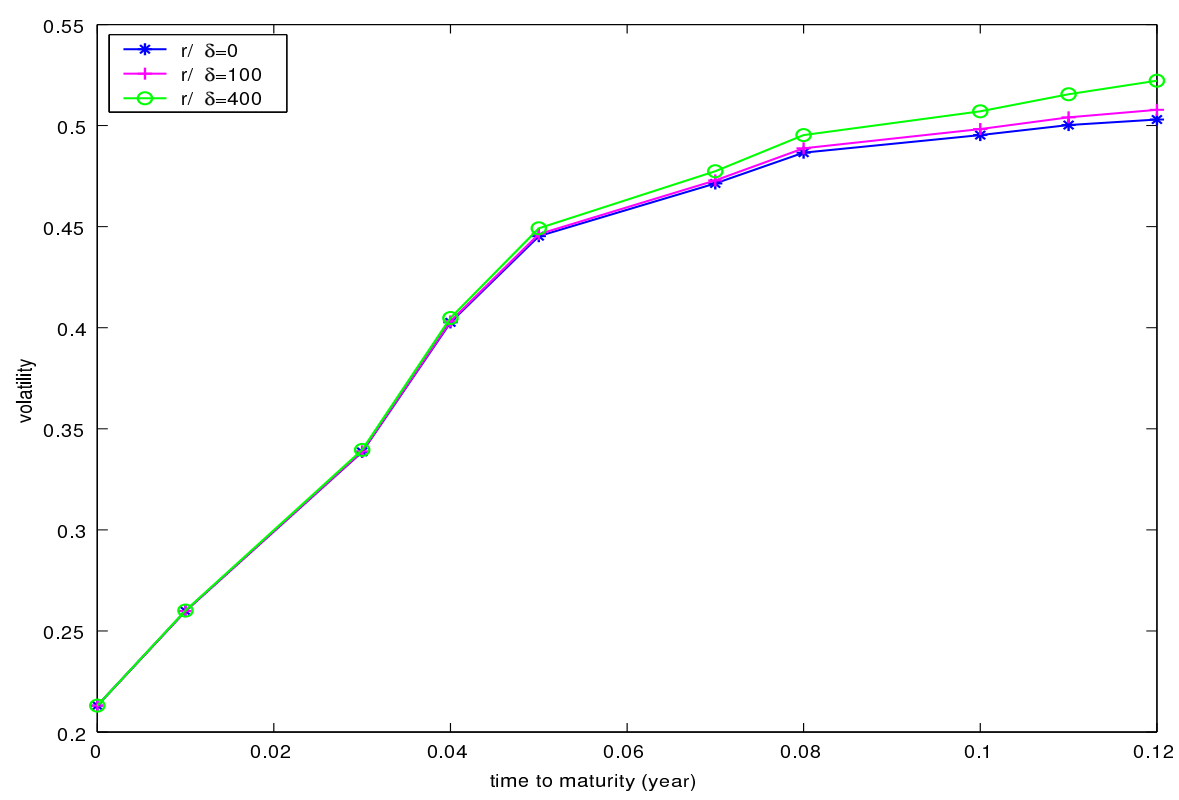

Figure 5. Relationship between Volatility and Time to Maturity for Crude Oil

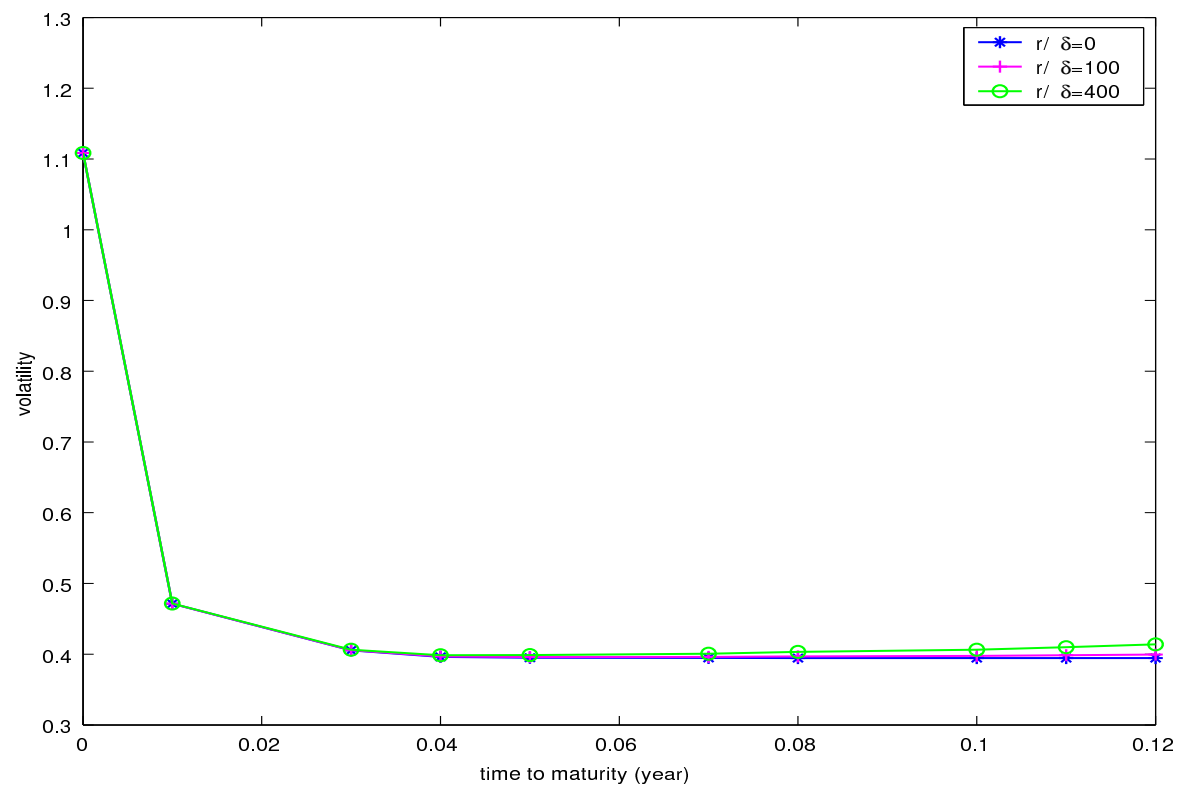

Figure 6. Relationship between Volatility and Time to Maturity for Heating Oil 


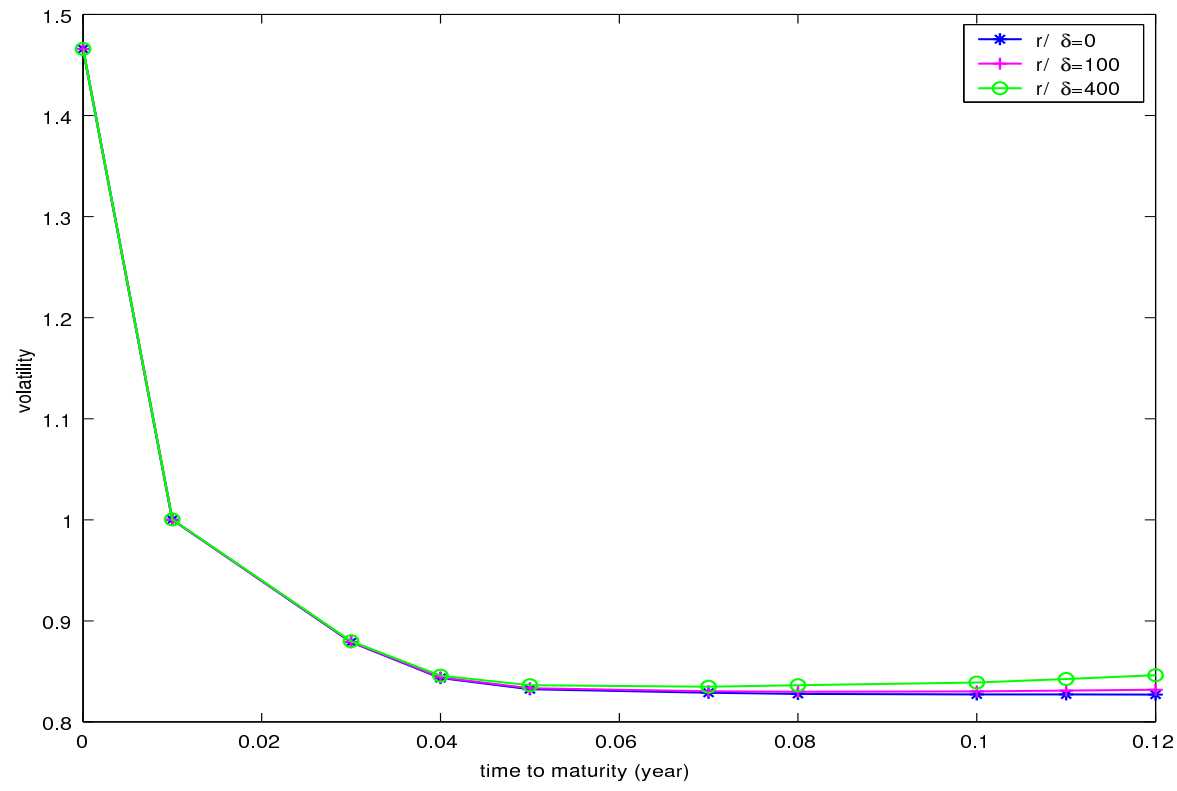

Figure 7. Relationship between Volatility and Time to Maturity for Natural Gas 
Panel A: WTI Crude Oil Futures Prices

\begin{tabular}{lrrrrrr}
\hline & $\mathrm{WTI}_{1}$ & \multicolumn{1}{c}{$\mathrm{WTI}_{2}$} & \multicolumn{1}{c}{$\mathrm{WTI}_{3}$} & \multicolumn{1}{c}{$\mathrm{WTI}_{4}$} & \multicolumn{1}{c}{$\mathrm{WTI}_{5}$} & $\mathrm{WTI}_{6}$ \\
\hline Mean & 45.96 & 46.03 & 45.99 & 45.87 & 45.71 & 45.55 \\
Median & 37.21 & 36.47 & 35.91 & 35.44 & 34.99 & 34.53 \\
Maximum & 110.33 & 109.17 & 107.94 & 106.90 & 106.06 & 105.44 \\
Minimum & 17.45 & 17.84 & 18.06 & 18.27 & 18.44 & 18.60 \\
Std. Dev. & 20.66 & 20.92 & 21.14 & 21.32 & 21.49 & 21.65 \\
Skewness & 0.81 & 0.76 & 0.72 & 0.69 & 0.67 & 0.66 \\
Kurtosis & 2.79 & 2.59 & 2.44 & 2.33 & 2.24 & 2.17 \\
\hline
\end{tabular}

\section{Panel B: Heating Oil Futures Prices}

\begin{tabular}{lrrrrrr}
\hline & \multicolumn{1}{c}{$\mathrm{HO}_{1}$} & \multicolumn{1}{c}{$\mathrm{HO}_{2}$} & \multicolumn{1}{c}{$\mathrm{HO}_{3}$} & \multicolumn{1}{c}{$\mathrm{HO}_{4}$} & \multicolumn{1}{c}{$\mathrm{HO}_{5}$} & \multicolumn{1}{c}{$\mathrm{HO}_{6}$} \\
\hline Mean & 127.86 & 128.27 & 128.35 & 128.15 & 127.82 & 127.44 \\
Median & 101.90 & 99.83 & 98.53 & 96.25 & 94.02 & 91.97 \\
Maximum & 314.83 & 306.45 & 301.55 & 301.05 & 301.10 & 301.50 \\
Minimum & 49.99 & 51.31 & 51.71 & 51.96 & 51.52 & 50.87 \\
Std. Dev. & 59.54 & 60.28 & 60.98 & 61.52 & 61.93 & 62.30 \\
Skewness & 0.73 & 0.68 & 0.65 & 0.64 & 0.63 & 0.62 \\
Kurtosis & 2.58 & 2.37 & 2.21 & 2.11 & 2.04 & 2.00 \\
\hline
\end{tabular}

Panel C: Natural Gas Futures Prices

\begin{tabular}{lrrrrrr}
\hline & $\mathrm{NG}_{1}$ & $\mathrm{NG}_{2}$ & $\mathrm{NG}_{3}$ & $\mathrm{NG}_{4}$ & $\mathrm{NG}_{5}$ & $\mathrm{NG}_{6}$ \\
\hline Mean & 6.01 & 6.16 & 6.27 & 6.31 & 6.35 & 6.36 \\
Median & 5.94 & 6.11 & 6.19 & 6.09 & 6.11 & 6.18 \\
Maximum & 15.38 & 15.43 & 15.29 & 14.91 & 14.67 & 14.22 \\
Minimum & 1.83 & 1.98 & 2.08 & 2.18 & 2.26 & 2.33 \\
Std. Dev. & 2.27 & 2.32 & 2.36 & 2.34 & 2.33 & 2.30 \\
Skewness & 0.90 & 0.90 & 0.90 & 0.73 & 0.60 & 0.39 \\
Kurtosis & 4.75 & 4.72 & 4.57 & 3.83 & 3.28 & 2.43 \\
\hline
\end{tabular}

Table 1. Basic Statistics of Futures Prices

$$
\begin{gathered}
\hat{x}_{t}^{-}=f_{1}\left(\hat{x}_{t-1}, \hat{\delta}_{t-1}, 0\right) \\
\hat{\delta}_{t}^{-}=f_{2}\left(\hat{x}_{t-1}, \hat{\delta}_{t-1}, 0\right) \\
\Phi_{t}^{-}=A_{t} \Phi_{t-1} A_{t}^{T}+W_{t} Q_{t} W_{t}^{T}
\end{gathered}
$$

Table 2. KF Time Update Equations 


$$
\begin{gathered}
K_{t}=\Phi_{t}^{-} B_{t}^{T}\left(B_{t} \Phi_{t}^{-} B_{t}^{T}+V_{t} R_{t} V_{t}^{T}\right)^{-1} \\
\hat{x}_{t}=\hat{x}_{t}^{-}+K_{t}\left(y_{t}-h_{1}\left(\hat{x}_{t}^{-}, \hat{\delta}_{t}^{-}, 0\right)\right) \\
\hat{\delta}_{t}=\hat{\delta}_{t}^{-}+K_{t}\left(y_{t}-h_{1}\left(\hat{x}_{t}^{-}, \hat{\delta}_{t}^{-}, 0\right)\right) \\
\Phi_{t}=\left(I-K_{t} B_{t}\right) \Phi_{t}^{-}
\end{gathered}
$$

Table 3. KF Measurement Update Equations

\begin{tabular}{cccccccc}
\hline Parameters & $a$ & $\bar{\sigma}_{P}$ & $\kappa$ & $\bar{\mu}$ & $\bar{\sigma}_{\delta}$ & $\rho$ & $\lambda$ \\
\hline Estimates & $7.910 \times 10^{-6}$ & 0.234 & 4.149 & 0.082 & 10.799 & 0.627 & -0.959 \\
(Std. Err.) & $6.255 \times 10^{-8}$ & 0.000 & 0.000 & 0.000 & 0.000 & 0.000 & 0.000 \\
\hline Parameters & $m_{1}$ & $m_{2}$ & $m_{3}$ & $m_{4}$ & $m_{5}$ & $m_{6}$ & \\
\hline Estimates & $8.120 \times 10^{-4}$ & $9.208 \times 10^{-5}$ & $8.325 \times 10^{-5}$ & $1.657 \times 10^{-6}$ & $9.272 \times 10^{-5}$ & $3.456 \times 10^{-4}$ & \\
(Std. Err.) & $3.516 \times 10^{-7}$ & $3.772 \times 10^{-8}$ & $1.888 \times 10^{-7}$ & $2.570 \times 10^{-8}$ & $1.901 \times 10^{-7}$ & $1.362 \times 10^{-7}$ & \\
Loglike & $4.041 \times 10^{4}$ & & & & & & \\
AIC & $-8.080 \times 10^{4}$ & & & & & & \\
SIC & $-8.082 \times 10^{4}$ & & & & & & \\
\hline
\end{tabular}

Table 4. MR Price Model Parameter Estimation for Crude Oil Futures

\begin{tabular}{cccccccc}
\hline Parameters & $a$ & $\bar{\sigma}_{P}$ & $\kappa$ & $\bar{\mu}$ & $\bar{\sigma}_{\delta}$ & $\rho$ & $\lambda$ \\
\hline Estimates & 5.671 & 1.409 & 101.180 & 0.721 & 44.079 & 0.697 & 66.096 \\
(Std. Err.) & 0.000 & 0.000 & 0.000 & 0.000 & 0.000 & 0.000 & 0.000 \\
\hline Parameters & $m_{1}$ & $m_{2}$ & $m_{3}$ & $m_{4}$ & $m_{5}$ & $m_{6}$ & \\
\hline Estimates & $2.597 \times 10^{-3}$ & $1.718 \times 10^{-3}$ & $4.573 \times 10^{-4}$ & $1.467 \times 10^{-5}$ & $3.361 \times 10^{-4}$ & $1.443 \times 10^{-3}$ & \\
(Std. Err.) & $4.386 \times 10^{-7}$ & $2.570 \times 10^{-8}$ & $1.618 \times 10^{-7}$ & $2.820 \times 10^{-9}$ & $2.947 \times 10^{-8}$ & $1.032 \times 10^{-6}$ & \\
Loglike & $3.296 \times 10^{4}$ & & & & & & \\
AIC & $-6.590 \times 10^{4}$ & & & & & & \\
SIC & $-6.592 \times 10^{4}$ & & & & & & \\
\hline
\end{tabular}

Table 5. MR Price Model Parameter Estimation for Heating Oil Futures 


\begin{tabular}{cccccccc}
\hline Parameters & $a$ & $\bar{\sigma}_{P}$ & $\kappa$ & $\bar{\mu}$ & $\bar{\sigma}_{\delta}$ & $\rho$ & $\lambda$ \\
\hline Estimates & 0.639 & 2.107 & 75.318 & 0.033 & 6.718 & 1.000 & 6.088 \\
(Std. Err.) & 0.056 & 0.066 & 1.478 & 0.004 & 0.604 & 0.022 & 0.490 \\
\hline Parameters & $m_{1}$ & $m_{2}$ & $m_{3}$ & $m_{4}$ & $m_{5}$ & $m_{6}$ & \\
\hline Estimates & $1.714 \times 10^{-2}$ & $1.014 \times 10^{-2}$ & $3.569 \times 10^{-3}$ & $4.279 \times 10^{-4}$ & $2.210 \times 10^{-3}$ & $6.555 \times 10^{-3}$ & \\
(Std. Err.) & $4.780 \times 10^{-4}$ & $3.126 \times 10^{-4}$ & $1.132 \times 10^{-4}$ & $7.520 \times 10^{-6}$ & $7.318 \times 10^{-5}$ & $1.978 \times 10^{-4}$ & \\
Loglike & $2.365 \times 10^{4}$ & & & & & & \\
AIC & $-4.728 \times 10^{4}$ & & & & & & \\
SIC & $-4.731 \times 10^{4}$ & & & & & & \\
\hline
\end{tabular}

Table 6. MR Price Model Parameter Estimation for Natural Gas Futures

\begin{tabular}{lrcc}
\hline Parameters & \multicolumn{1}{c}{$\kappa_{r}$} & $\mu_{r}$ & $\overline{\boldsymbol{\sigma}}_{r}$ \\
\hline Estimates & 0.333 & 0.014 & 0.057 \\
Standard errors & 0.178 & 0.009 & 0.001 \\
Log likelihood & 12,023 & & \\
AIC & $-24,039$ & & \\
SIC & $-24,045$ & & \\
\hline
\end{tabular}

Table 7. CIR Model Parameter Estimation of 3-Month US Treasury Bill

\begin{tabular}{cccccccc}
\hline Parameters & $a$ & $\bar{\sigma}_{P}$ & $\kappa$ & $\bar{\mu}$ & $\bar{\sigma}_{\delta}$ & $\rho$ & $\lambda$ \\
\hline Estimates & 1.030 & 0.462 & 31.744 & 0.146 & 20.495 & 0.020 & -4.827 \\
(Std. Err.) & 0.000 & 0.000 & 0.001 & 0.000 & 0.000 & 0.001 & 0.000 \\
\hline Parameters & $m_{1}$ & $m_{2}$ & $m_{3}$ & $m_{4}$ & $m_{5}$ & $m_{6}$ & \\
\hline Estimates & $2.619 \times 10^{-3}$ & $7.018 \times 10^{-4}$ & $1.602 \times 10^{-4}$ & $1.059 \times 10^{-5}$ & $1.110 \times 10^{-4}$ & $3.751 \times 10^{-4}$ & \\
(Std. Err.) & $3.349 \times 10^{-6}$ & $2.413 \times 10^{-6}$ & $4.070 \times 10^{-6}$ & $1.062 \times 10^{-7}$ & $2.721 \times 10^{-6}$ & $9.462 \times 10^{-6}$ & \\
Loglike & $3.786 \times 10^{4}$ & & & & & & \\
AIC & $-7.569 \times 10^{4}$ & & & & & & \\
SIC & $-7.572 \times 10^{4}$ & & & & & & \\
\hline
\end{tabular}

Table 8. MCR Price Model Parameter Estimation for Crude Oil Futures 


\begin{tabular}{cccccccc}
\hline Parameters & $a$ & $\bar{\sigma}_{P}$ & $\kappa$ & $\bar{\mu}$ & $\bar{\sigma}_{\delta}$ & $\rho$ & $\lambda$ \\
\hline Estimates & 0.885 & 1.053 & 156.550 & 0.194 & 67.902 & 0.855 & 2.910 \\
(Std. Err.) & 0.000 & 0.000 & 0.000 & 0.000 & 0.000 & 0.000 & 0.000 \\
\hline Parameters & $m_{1}$ & $m_{2}$ & $m_{3}$ & $m_{4}$ & $m_{5}$ & $m_{6}$ & \\
\hline Estimates & $3.155 \times 10^{-3}$ & $1.484 \times 10^{-3}$ & $4.011 \times 10^{-4}$ & $8.075 \times 10^{-5}$ & $4.718 \times 10^{-4}$ & $1.326 \times 10^{-3}$ & \\
(Std. Err.) & $1.174 \times 10^{-7}$ & $3.566 \times 10^{-7}$ & $7.495 \times 10^{-8}$ & $2.721 \times 10^{-8}$ & $6.443 \times 10^{-9}$ & $2.550 \times 10^{-7}$ & \\
Loglike & $3.305 \times 10^{4}$ & & & & & & \\
AIC & $-6.608 \times 10^{4}$ & & & & & & \\
SIC & $-6.610 \times 10^{4}$ & & & & & & \\
\hline
\end{tabular}

Table 9. MCR Price Model Parameter Estimation for Heating Oil Futures

\begin{tabular}{cccccccc}
\hline Parameters & $a$ & $\bar{\sigma}_{P}$ & $\kappa$ & $\bar{\mu}$ & $\bar{\sigma}_{\delta}$ & $\rho$ & $\lambda$ \\
\hline Estimates & 1.345 & 1.211 & 96.571 & 0.243 & 34.825 & 0.751 & 18.015 \\
(Std. Err.) & 0.000 & 0.000 & 0.000 & 0.000 & 0.000 & 0.000 & 0.000 \\
\hline Parameters & $m_{1}$ & $m_{2}$ & $m_{3}$ & $m_{4}$ & $m_{5}$ & $m_{6}$ & \\
\hline Estimates & $1.692 \times 10^{-2}$ & $1.001 \times 10^{-2}$ & $3.545 \times 10^{-3}$ & $4.487 \times 10^{-4}$ & $2.369 \times 10^{-3}$ & $6.616 \times 10^{-3}$ & \\
(Std. Err.) & $1.412 \times 10^{-7}$ & $3.063 \times 10^{-8}$ & $9.419 \times 10^{-7}$ & $1.957 \times 10^{-8}$ & $8.033 \times 10^{-8}$ & $5.802 \times 10^{-8}$ & \\
Loglike & $2.359 \times 10^{4}$ & & & & & & \\
AIC & $-4.715 \times 10^{4}$ & & & & & & \\
SIC & $-4.718 \times 10^{4}$ & & & & & & \\
\hline
\end{tabular}

Table 10. MCR Price Model Parameter Estimation for Natural Gas Futures 